\title{
Control of Botrytis mold of the new seedless grape 'BRS Vitoria' during cold storage
}

\author{
Khamis Youssef ${ }^{a}, *$, Sergio Ruffo Roberto ${ }^{b}$, Francelize Chiarotti $^{\mathrm{b}}$, Renata Koyama ${ }^{\mathrm{b}}$, \\ Ibrar Hussain $^{\mathrm{b}}$, Reginaldo Teodoro de Souza ${ }^{\mathrm{c}}$ \\ a Agricultural Research Center - Plant Pathology Research Institute, 9 Gamaa St., 12619 Giza, Egypt \\ b Department of Agronomy, Londrina State University, Celso Garcia Cid Road, km 380, P.O. Box 10.011, ZIP 86057-970 Londrina, PR, Brazil

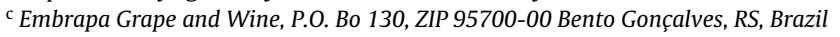

\section{A R T I C L E I N F O}

\section{Article history:}

Received 19 May 2015

Received in revised form 7 July 2015

Accepted 14 July 2015

\section{Keywords:}

Botrytis cinerea

$\mathrm{SO}_{2}$

Table grape

Cold storage

Grape quality

\begin{abstract}
A B S T R A C T
The objective of this work was to evaluate the incidence of gray mold of the new seedless table grape 'BRS Vitoria' grown under subtropical conditions, during the cold storage. Grape bunches were obtained from a commercial field trained on overhead trellis and located at Marialva, state of Parana (PR) (South Brazil). The trials were conducted on two consecutive seasons, regular and out of season crops of 2013. Grapes were subjected to the following treatments in a cold chamber: (i) cold storage at $0^{\circ}$ (control); (ii) cold storage at $0^{\circ} \mathrm{C}$ with $\mathrm{SO}_{2}$ pad; (iii) cold storage at $0^{\circ}$ and inoculated with Botrytis cinerea suspension; (iv) cold storage at $0^{\circ} \mathrm{C}$ with $\mathrm{SO}_{2}$ pad and inoculated with $B$. cinerea suspension. The randomized design was used as statistical model with four treatments and five replicates, with 20 bunches per plot. The incidence of gray mold on grapes was evaluated at 30 days after the beginning of cold storage and at 7 days at room temperature after the end of cold storage. Grape physicochemical variables, such as bunch mass, berry firmness, bunch mass loss, skin color, soluble solids (SS), titratable acidity (TA) and SS/TA were evaluated at the beginning and 30 days after the period of cold storage. The results of this study showed that a good reduction of gray mold was achieved by $\mathrm{SO} 2$ during cold storage and shelf life periods. Also, bunch mass, berry firmness, mass loss, color, SS, TA and SS/TA of the grape tested was not negatively affected by $\mathrm{SO}_{2}$ treatment. A good control of gray mold could be achieved on 'BRS Vitoria' table grapes by sulfur dioxide during storage without affecting fruit quality.
\end{abstract}

(c) 2015 Elsevier B.V. All rights reserved.

\section{Introduction}

Among the large number of nutraceutical fruits grown in the world, table grapes are one of the most important sources of phenolic compounds, which have beneficial effects on human health by acting to neutralize free radicals (Orak, 2007; Rastija et al., 2009). Viticulture has grown in many countries, due to the grape nutraceutical properties, especially because the release of new seedless cultivars recommended for local and export markets, which are preferred by consumers worldwide (Uquillas et al., 2013).

Recently released, 'BRS Vitoria' is a novel cultivar of black seedless table grape recommended for cultivation in tropical and subtropical areas, with excellent horticultural performance, high bud fecundity and tolerance to downy mildew, the most important

\footnotetext{
* Corresponding author. Fax: +20 235723146.

E-mail addresses: youssefeladawy@agr.uniba.it, youssefeladawy@arc.sci.eg (K. Youssef).
}

disease which affects grapevines in subtropical areas. Yields can be higher than $30 \mathrm{tha}^{-1}$ and it is an excellent option for overseas market because its firmness and flavor (Maia et al., 2014).

In some subtropical areas, the obtainment of two crops of table grape per year (regular and out of season crops) is possible due the mild winter and the use of budburst stimulators. The regular crop starts from the end of grapevine dormancy in late winter, and the harvest occurs during summer. Right after that, a new cycle is forced, the grapevines are pruned and forced to sprout again by using budburst stimulators, and an out of season crop is obtained during autumn (Ricce et al., 2013).

However, in this intensive production system, harvest can occur during high favorable conditions for the development of postharvest fungal diseases (Genta et al., 2010; Buffara et al., 2014), and can limit long-distance transportation of fresh grapes.

Gray mold, caused by Botrytis cinerea Pers. Fr., is considered to be the main postharvest decay of table grapes resulting in severe loss during cold storage transportation overseas (Pearson and Goheen, 1988). It can develop in the vineyard and even more after harvest, 
during long-distance transport, cold storage, and shelf-life. The control of gray mold is very difficult since postharvest treatments with synthetic fungicides are not allowed in many countries.

The integration of canopy management and fungicide treatments before harvest with the use of $\mathrm{SO}_{2}$ and cold storage after harvest are the commercial strategies implemented to control this disease (Gubler et al., 1987; Luvisi et al., 1992; Palou et al., 2002; Droby and Lichter, 2004). Nevertheless, fungicide use is strictly regulated by national and international legislations, and currently very few active ingredients are allowed against postharvest diseases (Smilanick et al., 2010).

So far, it is unknown the behavior of 'BRS Vitoria' table seedless grape during cold storage in relation to the gray mold development, especially when the vines are grown in a two crops per year system. Thus, the evaluation of techniques to avoid grape losses during postharvest are needed to keep quality and profit. In this context, the objective of this work was to evaluate the incidence of gray mold of the new seedless table grape 'BRS Vitoria' grown under subtropical conditions, during the cold storage.

\section{Material and methods}

\subsection{Experimental location}

Grape bunches were obtained from a commercial field of 'BRS Vitoria' seedless table grape grafted on 'IAC 766' rootstock, from 4year-old vines trained on overhead trellis located at Marialva, state of Parana (PR) (South Brazil) (23⒉ $29^{\prime} \mathrm{S}, 51^{\circ} 47^{\prime} \mathrm{W}$, altitude $570 \mathrm{~m}$ ). Samples were collected from two consecutive crops, regular and out of season in 2013. According to the Köppen classification, the climate is type $\mathrm{Cfa}$, i.e., subtropical climate with an average temperature in the coldest month below $18^{\circ} \mathrm{C}$ and average temperature in the warmest month above $22^{\circ} \mathrm{C}$. The maximum temperature is $31^{\circ} \mathrm{C}$ and the average annual rainfall is $1596 \mathrm{~mm}$, with a tendency of concentrated rainfall in summer months. The field was selected because of its historical of gray mold incidence.

\subsection{Fungal identification and suspension}

Botrytis cinerea, used in this study, was isolated from infected grapes showing typical gray mold symptoms, purified and identified morphologically and molecularly as described by Youssef and Roberto (2014a). The isolates were maintained on PDA slants and stored at $4{ }^{\circ} \mathrm{C}$ for further use.

Fungal conidia were harvested from 2-week-old PDA cultures of $B$. cinerea grown at $23 \pm 1{ }^{\circ} \mathrm{C}$. A volume of $5 \mathrm{~mL}$ of sterile water, containing $0.05 \%(\mathrm{v} / \mathrm{v})$ Tween 80 , was added to a Petri plate culture. The conidia were gently dislodged from the surface with a sterile glass rod, and suspensions were filtered through three layers of cheesecloth to remove any adhering mycelia. The suspensions were diluted with sterile water and the concentration was determined with a hemacytometer. Further dilutions with sterile water were made to obtain the desired conidial concentrations. B. cinerea suspension $\left(10^{6}\right.$ conidia $\left.\mathrm{mL}^{-1}\right)$ was used for grape inoculation.

\subsection{Treatments and storage}

Grapes were harvested at full maturity when soluble solids content reached around $16^{\circ}$ Brix, and then, bunches were subjected to the following treatments into a cold chamber: (i) cold storage at $0^{\circ} \mathrm{C}$ (control); (ii) cold storage at $0{ }^{\circ} \mathrm{C}$ with $\mathrm{SO}_{2}$ pad; (iii) cold storage at $0^{\circ}$ and inoculated with Botrytis cinerea suspension; (iv) cold storage at $0{ }^{\circ} \mathrm{C}$ with $\mathrm{SO}_{2}$ pad and inoculated with $B$. cinerea suspension. The inoculation was carried out by spraying a conidial suspension $\left(10^{6}\right.$ conidia $\left.\mathrm{mL}^{-1}\right)$. The completely randomized experimental design was used as statistical model with four treatments and five replicates, with 20 bunches per plot. Bunches were arranged in $23 \mathrm{~cm} \times 16 \mathrm{~cm} \times 9 \mathrm{~cm}$ carton boxes, covered with plastic bag measuring $30 \mathrm{~cm} \times 45 \mathrm{~cm}$, and stored in a cold chamber at $0 \pm 1{ }^{\circ} \mathrm{C}$ for one month followed by one week of shelf-life at $22 \pm 2{ }^{\circ} \mathrm{C}$ and high $\mathrm{RH}$. For treatments with $\mathrm{SO}_{2}$, one generator pad measuring $13 \mathrm{~cm} \times 23 \mathrm{~cm}$ per box provided with fast and slow release phases of sodium metabisulfite $\left(\mathrm{Na}_{2} \mathrm{~S}_{2} \mathrm{O}_{5}\right), 98 \%$ (Matesa ${ }^{\circledR}$, Grapeguard, Chile) was used at the cold storage period only, and subsequently removed at the beginning of shelf-life.

\subsection{Gray mold incidence}

The incidence of gray mold on grapes was evaluated at 30 days after the beginning of cold storage and at 7 days at room temperature after the end of cold storage. The disease incidence was then obtained by the formula: Disease incidence $(\%)=($ Number of decayed bunches/Total number of bunches) $\times 100$ (Youssef and Roberto, 2014a).

\subsection{Physical properties for quality measurements}

The berry firmness or maximum compression force was performed with a texture analyser TA.XTplus (Stable Micro Systems, Surrey, England), analyzing the equatorial position of 10 berries with pedicels per plot. Each berry was placed on the base of the equipment and compressed using a cylindrical probe with a diameter of $35 \mathrm{~mm}$ parallel to the base. A constant force of $0.05 \mathrm{~N}$ at a speed of $1.0 \mathrm{~mm} \mathrm{~s}^{-1}$ was applied to promote the cracking of the sample. The berry firmness $(\mathrm{N})$ was then determined (Borges et al., 2012).

The mass loss (\%) during postharvest storage was determined by periodical weighing, and calculated by dividing the mass change during storage by the original mass: Mass loss $(\%)=\left[\left(M_{\mathrm{i}}-M_{\mathrm{s}}\right) / M_{\mathrm{i}}\right] \times 100$, where $M_{\mathrm{i}}=$ initial mass and $M_{\mathrm{s}}=$ mass at examined time (Mattiuz et al., 2009).

Berry color was analyzed using a colorimeter Minolta ${ }^{\circledR}$ CR-10 to obtain the following variables from the equatorial portion of berries ( $n=2$ per berry): $L^{*}$ (lightness), $C^{*}$ (chroma) and $h^{\circ}$ (hue) (Koyama et al., 2014). Lightness values may range from 0 (black) to 100 (white). Chroma indicates the purity or intensity of color, the distance from gray (achromatic) toward a pure chromatic color and is calculated from the $a^{*}$ and $b^{*}$ values of the CIELab scale system, starts from zero for a completely neutral color, and does not have an arbitrary end, but intensity increases with magnitude. Hue refers to the color wheel and is measured in angles; green, yellow and red correspond to 180,90 and $0^{\circ}$, respectively (McGuire, 1992; Lancaster et al., 1997; Peppi et al., 2006).

\subsection{Chemical properties for quality measurements}

For chemical analysis, 10 berries were collected from each box (replicate) totalizing 50 berries per each treatment. The juice from 10 grapes for each replicate was used to determine soluble solids (SS) and titratable acidity (TA). SS was determined with a digital refractometer (Krüss, Hamburg, Germany) at $20^{\circ} \mathrm{C}$, and the results were expressed in ${ }^{\circ}$ Brix. The $\mathrm{pH}$ of the juice was recorded using a Jenway 3510 bench pH meter, Staffordshire, UK and then TA was determined by potentiometric titration with $0.1 \mathrm{~N} \mathrm{NaOH}$ up to $\mathrm{pH}$ 8.2, using $10 \mathrm{~mL}$ of diluted juice in $40 \mathrm{~mL}$ distilled $\mathrm{H}_{2} \mathrm{O}$, and the results were expressed in\% of tartaric acid (Youssef and Roberto, 2014b).

The grape physicochemical analysis was evaluated at the beginning and 30 days after the period of cold storage. 


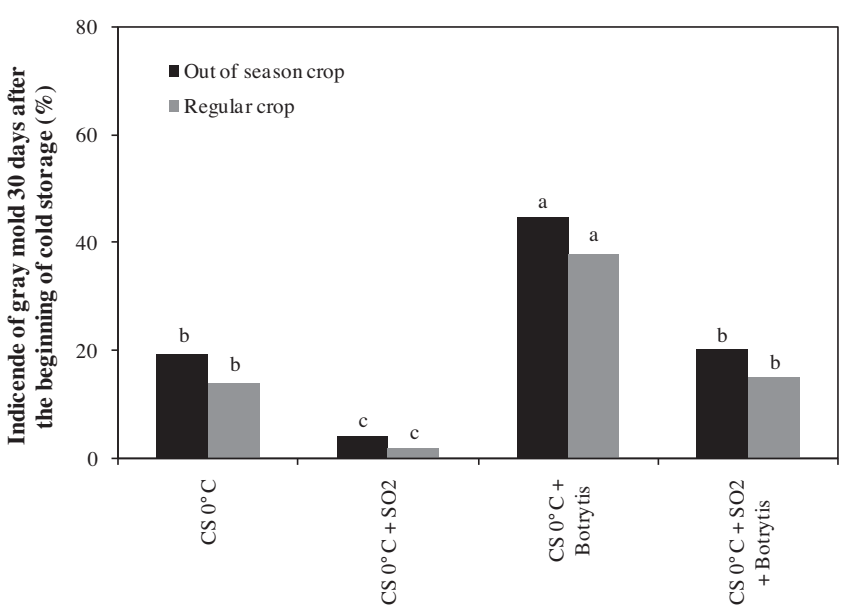

Fig. 1. Incidence of gray mold (\%) 30 days after the beginning of cold storage (CS) of 'BRS Vitoria' seedless table grape, during out of season and regular crops. Columns followed by unlike letters, in relation to the treatments within each individual crop, are statistically different according to Fisher's protected LSD test $(P \leq 0.05)$.

\subsection{Statistical analysis}

Percentage data were arcsine-square root transformed to normalize variance before ANOVA analysis. All data were subjected to analysis of variance using Statistica 6.0 software. Mean values of treatments were compared by using Fisher's protected LSD test and judged at $P \leq 0.05$ level. In all cases, experiments were repeated twice and average was shown. Data in the graphs are untransformed percentage of rotted grape berries.

\section{Results}

\subsection{Gray mold incidence (\%)}

Overall under natural conditions, after one month of cold storage at $0 \pm 1{ }^{\circ} \mathrm{C}$, the natural incidence of postharvest decay was mostly caused by $B$. cinerea. The incidence of decay caused by other fungi i.e. Alternaria spp., Penicillium spp. and Aspergillus spp. was tiny.

When grapes from out of season crop were subjected to $\mathrm{SO}_{2}$, the incidence of gray mold was reduced by $79.4 \%$ as compared to its control. From regular crop, the incidence of gray mold was reduced by $85.5 \%$ as compared to its control. Under artificial conditions, for out of season crop, sulfur dioxide reduced the incidence of Botrytis mold by $54.8 \%$ as compared to the control. In regular crop, the incidence was reduced by $60 \%$ as compared to control (Fig. 1).

After seven days of shelf-life at $22 \pm 2{ }^{\circ} \mathrm{C}$ and high $\mathrm{RH}$, under natural conditions, when grapes from out of season crop were subjected to $\mathrm{SO}_{2}$, the incidence of gray mold was reduced by $76.3 \%$ as compared to its control. In regular crop, the incidence of gray mold was reduced by $73.3 \%$ as compared to its control. Under artificial conditions, sulfur dioxide reduced the incidence of Botrytis mold by $61.5 \%$ and $53 \%$ for out of season crop and regular crop, respectively, as compared to control (Fig. 2).

\subsection{Physical properties for quality measurements}

For both seasons, there were no significant differences among treatments neither in terms of bunch mass, nor in terms of beginning of cold storage and after 30 days of cold storage. During out of season crop, bunch mass ranged from 322.8 to $353.2 \mathrm{~g}$ and 320 to $349 \mathrm{~g}$ at the beginning of cold storage and after 30 days of cold storage, respectively. In regular crop, bunch mass ranged from 367 to $387 \mathrm{~g}$ and 360 to $376 \mathrm{~g}$ at the beginning and after 30 days of cold storage, respectively.

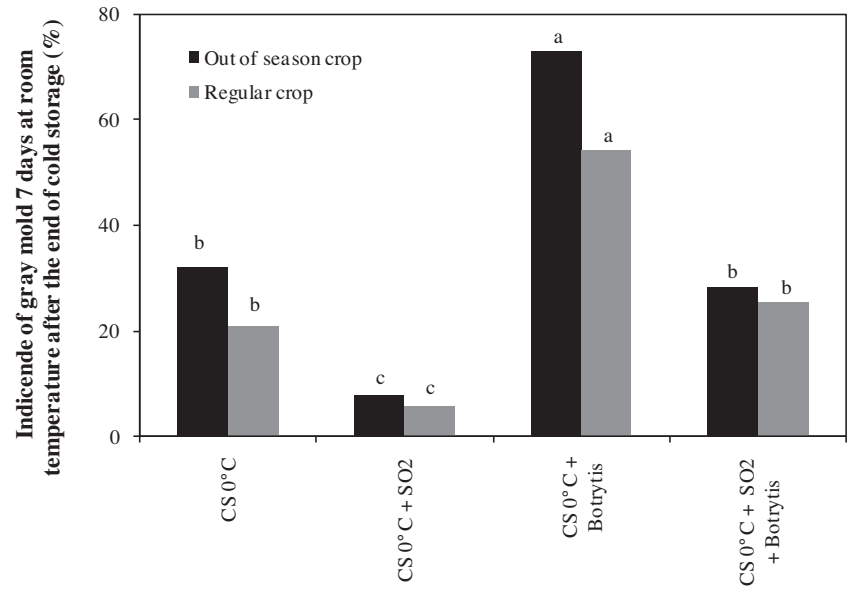

Fig. 2. Incidence of gray mold (\%) 7 days at room temperature after the end of cold storage (CS) of 'BRS Vitoria' seedless table grape, during out of season and regular crops. Columns followed by unlike letters, in relation to the treatments within each individual crop, are statistically different according to Fisher's protected LSD test $(P \leq 0.05)$.

Regarding berry firmness from out of season crop, means ranged from 18.4 to $19.9 \mathrm{~N}$ and 11.7 to 12.4 at the beginning of cold storage and after 30 days of cold storage, respectively. In regular crop, berry firmness ranged from 29.5 to $31.1 \mathrm{~N}$ and 17 to 23.6 at the beginning and after 30 days of cold storage, respectively.

Generally, grape mass loss after 30 days of cold storage was not influenced by the treatments and no statistical differences were found among all treatments (Table 1 ). After 30 days of cold storage, the mass loss varied from 1.9 to $3.8 \%$.

In regard to the berry color analyzed at the beginning of cold storage and 30 days after the beginning of cold storage (Table 2), it can be observed that, in all cases, no significant differences were observed between treatments in both out of season and regular crops. In particular, during out of season crop, $L^{*}$ ranged from 22.6 to 23.2 and 22.5 to 23.5 at the beginning of cold storage and after 30 days of cold storage, respectively. $L^{*}$ means of grapes from regular crop ranged from 23.3 to 24.3 and 23.8 to 24.5 at the beginning and after 30 days of cold storage, respectively.

During out of season crop, $C^{*}$ ranged from 2.1 to 2.2 and 2.4 to 2.7 at the beginning of cold storage and after 30 days of cold storage, respectively. In regular crop, $C^{*}$ ranged from 2.3 to 2.6 and 2.6 to 2.9 at the beginning and after 30 days of cold storage, respectively.

During out of season crop, $h^{\circ}$ ranged from 153.8 to 158.8 and 159.5 to 171.9 at the beginning of cold storage and after 30 days of cold storage, respectively. In regular crop, $h^{\circ}$ ranged from 147.9 to 165.1 and 155.1 to 169.7 at the beginning and after 30 days of cold storage, respectively (Table 2 ) indicating that the sulfur dioxide had no negative effect on 'BRS Vitoria' berries color.

\subsection{Chemical properties for quality measurements}

At the beginning and 30 days after the period of cold storage, no significant differences were found between the chemical properties of berries between treatments, regarding soluble solids (SS), titratable acidity (TA) and their ratio SS/TA from out of season and regular crops (Table 3).

During out of season crop, SS was 16.2 and ranged from 15.7 to $16.1^{\circ}$ Brix at the beginning of cold storage and after 30 days of cold storage, respectively. In regular crop, SS ranged from 16.5 to 16.9 and 16.2 to $17{ }^{\circ}$ Brix at the beginning and after 30 days of cold storage, respectively.

For out of season grapes, the means of TA was $0.8 \%$ for all treatments at the beginning of cold storage and ranged from 0.7 to 0.8 
Table 1

Bunch mass, berry firmness and mass loss of 'BRS Vitoria' seedless table grape at the beginning and 30 days of cold storage during out of season and regular crops.

\begin{tabular}{|c|c|c|c|c|c|c|c|}
\hline \multirow[t]{4}{*}{ Treatments } & \multicolumn{3}{|l|}{ Bunch mass (g) } & \multicolumn{3}{|c|}{ Berry firmness $(\mathrm{N})$} & \multirow[t]{2}{*}{ Mass loss (\%) } \\
\hline & \multicolumn{6}{|c|}{ Beginning of cold storage } & \\
\hline & \multicolumn{7}{|l|}{ Crop } \\
\hline & Out of season & \multicolumn{2}{|r|}{ Regular } & \multicolumn{2}{|c|}{ Out of season } & Regular & - \\
\hline $\mathrm{CS} 0^{\circ} \mathrm{C}$ & $337.2 \mathrm{a}$ & & 367.0a & 19 & & $31.1 \mathrm{a}$ & - \\
\hline $\mathrm{CS} 0^{\circ} \mathrm{C}+\mathrm{SO}_{2}$ pad & $353.2 \mathrm{a}$ & & $382.0 \mathrm{a}$ & 18 & & $29.8 a$ & - \\
\hline $\mathrm{CS} 0^{\circ} \mathrm{C}+$ Botrytis inoculation & $322.8 a$ & & 381.0a & 19 & & $30.0 \mathrm{a}$ & - \\
\hline $\mathrm{CS} 0^{\circ} \mathrm{C}+\mathrm{SO}_{2}$ pad + Botrytis inoculation & $351.2 \mathrm{a}$ & & 387.0a & 18 & & $29.5 a$ & - \\
\hline \multirow[t]{4}{*}{ Treatments } & \multicolumn{3}{|l|}{ Bunch mass (g) } & \multicolumn{2}{|c|}{ Berry firmness $(\mathrm{N})$} & \multicolumn{2}{|l|}{ Mass loss (\%) } \\
\hline & \multicolumn{7}{|c|}{30 days after the beginning of cold storage } \\
\hline & \multicolumn{7}{|l|}{ Crop } \\
\hline & Out of season & \multicolumn{2}{|l|}{ Regular } & Out of season & Regular & Out of season & Regular \\
\hline $\mathrm{CS} 0^{\circ} \mathrm{C}$ & $332.2 \mathrm{a}$ & \multicolumn{2}{|l|}{$360.0 \mathrm{a}$} & $12.4 \mathrm{a}$ & $23.6 a$ & $1.5 \mathrm{a}$ & $1.9 \mathrm{a}$ \\
\hline $\mathrm{CS} 0^{\circ} \mathrm{C}+\mathrm{SO}_{2}$ pad & 349.0a & \multicolumn{2}{|l|}{$371.0 \mathrm{a}$} & $11.7 \mathrm{a}$ & $20.8 \mathrm{a}$ & $1.1 \mathrm{a}$ & $2.9 \mathrm{a}$ \\
\hline $\mathrm{CS} 0^{\circ} \mathrm{C}+$ Botrytis inoculation & 320.0a & \multicolumn{2}{|l|}{ 366.0a } & $12.3 \mathrm{a}$ & $19.2 \mathrm{a}$ & $1.0 \mathrm{a}$ & $3.8 \mathrm{a}$ \\
\hline $\mathrm{CS} 0^{\circ} \mathrm{C}+\mathrm{SO}_{2}$ pad + Botrytis inoculation & $347.8 \mathrm{a}$ & \multicolumn{2}{|l|}{$376.0 a$} & $11.7 \mathrm{a}$ & $17.0 \mathrm{a}$ & $0.9 \mathrm{a}$ & $2.8 \mathrm{a}$ \\
\hline
\end{tabular}

CS, cold storage; means within columns followed by the same letters are not statistically different by Fisher's protected LSD test ( $P \leq 0.05)$.

\section{Table 2}

Luminosity $\left(L^{*}\right)$, chroma $\left(C^{*}\right)$ e hue angle $\left(h^{\circ}\right)$ of 'BRS Vitoria' seedless table grape at the beginning and 30 days of cold storage during out of season and regular crops.

\begin{tabular}{|c|c|c|c|c|c|c|}
\hline \multirow[t]{4}{*}{ Treatments } & \multicolumn{2}{|l|}{$L^{*}$} & \multicolumn{2}{|l|}{$C^{*}$} & \multicolumn{2}{|l|}{$h^{\circ}$} \\
\hline & \multicolumn{6}{|c|}{ Beginning of cold storage } \\
\hline & \multicolumn{6}{|l|}{ Crop } \\
\hline & Out of season & Regular & Out of season & Regular & Out of season & Regular \\
\hline $\mathrm{CS} 0^{\circ} \mathrm{C}$ & $22.9 a$ & $23.3 a$ & $2.2 \mathrm{a}$ & $2.4 \mathrm{a}$ & $158.8 \mathrm{a}$ & $152.9 a$ \\
\hline $\mathrm{CS} 0^{\circ} \mathrm{C}+\mathrm{SO}_{2}$ pad & $22.6 a$ & $24.0 \mathrm{a}$ & $2.1 \mathrm{a}$ & $2.5 a$ & $154.3 a$ & $165.1 \mathrm{a}$ \\
\hline $\mathrm{CS} 0^{\circ} \mathrm{C}+$ Botrytis inoculation & $23.0 \mathrm{a}$ & $24.3 a$ & $2.1 \mathrm{a}$ & $2.3 a$ & $153.8 \mathrm{a}$ & 157.1a \\
\hline $\mathrm{CS} 0^{\circ} \mathrm{C}+\mathrm{SO}_{2}$ pad + Botrytis inoculation & $23.2 \mathrm{a}$ & $23.8 \mathrm{a}$ & $2.2 \mathrm{a}$ & $2.6 a$ & $155.8 \mathrm{a}$ & 147.9a \\
\hline \multirow[t]{4}{*}{ Treatments } & \multicolumn{2}{|l|}{$L^{*}$} & \multicolumn{2}{|l|}{$C^{*}$} & \multicolumn{2}{|l|}{$h^{\circ}$} \\
\hline & \multicolumn{6}{|c|}{30 days after the beginning of cold storage } \\
\hline & \multicolumn{6}{|l|}{ Crop } \\
\hline & Out of season & Regular & Out of season & Regular & Out of season & Regular \\
\hline $\mathrm{CS} 0^{\circ} \mathrm{C}$ & $23.5 a$ & $23.8 \mathrm{a}$ & $2.4 \mathrm{a}$ & $2.8 \mathrm{a}$ & 171.9a & $159.4 a$ \\
\hline $\mathrm{CS} 0^{\circ} \mathrm{C}+\mathrm{SO}_{2}$ pad & $23.3 a$ & $24.5 \mathrm{a}$ & $2.4 \mathrm{a}$ & 2.9a & $167.4 a$ & 169.7a \\
\hline $\mathrm{CS} 0^{\circ} \mathrm{C}+$ Botrytis inoculation & $22.9 a$ & $24.2 \mathrm{a}$ & $2.7 \mathrm{a}$ & $2.8 \mathrm{a}$ & $159.5 a$ & $155.1 \mathrm{a}$ \\
\hline $\mathrm{CS} 0^{\circ} \mathrm{C}+\mathrm{SO}_{2}$ pad + Botrytis inoculation & $22.5 a$ & $24.4 a$ & $2.4 a$ & $2.6 a$ & $164.4 \mathrm{a}$ & $158.9 a$ \\
\hline
\end{tabular}

CS, cold storage; means within columns followed by the same letters are not statistically different by Fisher's protected LSD test $(P \leq 0.05)$.

Table 3

Soluble solids (SS), titratable acidity (TA), SS/TA of 'BRS Vitoria' seedless table grape at the beginning and 30 days of cold storage during out of season and regular crops.

\begin{tabular}{|c|c|c|c|c|c|c|}
\hline \multirow[t]{4}{*}{ Treatments } & \multicolumn{2}{|c|}{ Soluble $\quad$ solids-SS $\left({ }^{\circ}\right.$ Brix $)$} & \multicolumn{2}{|c|}{ Titratable acidity-TA (\%) } & \multicolumn{2}{|l|}{ SS/TA } \\
\hline & \multicolumn{6}{|c|}{ Beginning of cold storage } \\
\hline & \multicolumn{6}{|l|}{ Crop } \\
\hline & Out of season & Regular & Out of season & Regular & Out of season & Regular \\
\hline $\mathrm{CS} 0^{\circ} \mathrm{C}$ & $16.4 \mathrm{a}$ & $16.5 \mathrm{a}$ & $0.8 \mathrm{a}$ & $0.6 a$ & $20.3 a$ & $26.2 \mathrm{a}$ \\
\hline $\mathrm{CS} 0^{\circ} \mathrm{C}+\mathrm{SO}_{2}$ pad & $16.4 \mathrm{a}$ & $16.7 \mathrm{a}$ & $0.8 \mathrm{a}$ & $0.6 \mathrm{a}$ & $20.0 \mathrm{a}$ & 27.9a \\
\hline $\mathrm{CS} 0^{\circ} \mathrm{C}+$ Botrytis inoculation & $16.2 \mathrm{a}$ & $16.8 \mathrm{a}$ & $0.8 \mathrm{a}$ & $0.6 a$ & $20.3 a$ & $28.4 \mathrm{a}$ \\
\hline $\mathrm{CS} 0^{\circ} \mathrm{C}+\mathrm{SO}_{2}$ pad + Botrytis inoculation & $16.4 \mathrm{a}$ & $16.9 a$ & $0.8 \mathrm{a}$ & $0.6 a$ & $20.4 \mathrm{a}$ & $27.3 \mathrm{a}$ \\
\hline \multirow[t]{4}{*}{ Treatments } & Soluble solids-SS & $\left({ }^{\circ} \mathrm{Brix}\right)$ & Titratable ac & (\%) & SS/TA & \\
\hline & \multicolumn{6}{|c|}{30 days after the beginning of cold storage } \\
\hline & \multicolumn{6}{|l|}{ Crop } \\
\hline & Out of season & Regular & Out of season & Regular & Out of season & Regular \\
\hline $\mathrm{CS} 0^{\circ} \mathrm{C}$ & $15.9 a$ & 16.3a & $0.8 \mathrm{a}$ & $0.6 a$ & $22.7 \mathrm{a}$ & $28.6 a$ \\
\hline $\mathrm{CS} 0^{\circ} \mathrm{C}+\mathrm{SO}_{2}$ pad & $15.7 \mathrm{a}$ & $17.0 \mathrm{a}$ & $0.7 \mathrm{a}$ & $0.5 \mathrm{a}$ & 21.9a & 30.9a \\
\hline $\mathrm{CS} 0^{\circ} \mathrm{C}+$ Botrytis inoculation & $16.1 \mathrm{a}$ & $16.7 \mathrm{a}$ & $0.7 \mathrm{a}$ & $0.6 a$ & $21.3 \mathrm{a}$ & $30.0 \mathrm{a}$ \\
\hline $\mathrm{CS} 0^{\circ} \mathrm{C}+\mathrm{SO}_{2}$ pad + Botrytis inoculation & $15.9 a$ & $16.2 \mathrm{a}$ & $0.7 \mathrm{a}$ & $0.5 \mathrm{a}$ & $20.4 a$ & $30.1 \mathrm{a}$ \\
\hline
\end{tabular}

CS, cold storage; means within columns followed by the same letters are not statistically different by Fisher's protected LSD test $(P \leq 0.05)$. 
$\%$ after 30 days of cold storage. In regular crop, TA was $0.6 \%$ for all treatment and at the beginning of cold storage and ranged from 0.5 to $0.6 \%$ after 30 days of cold storage.

For out of season grapes, the SS/TA ratio ranged from 20 to 20.4 at the beginning of cold storage and ranged from 20.4 to 22.7 after 30 days of cold storage. In regular season, the SS/TA ratio ranged from 26.2 to 28.4 at the beginning of cold storage and ranged from 28.6 to 30.9 after 30 days of cold storage (Table 3 ).

\section{Discussion}

B. cinerea Pers. ex Fr., is the most common postharvest pathogen of table grapes in most regions of the world, leading to severe losses of table grapes after harvest (Cappellini et al., 1986).

The fact that $B$. cinerea strains resistant to fungicides are very common emphasizes the need for an accurate adoption of Fungicide Resistance Action Committee (FRAC) guidelines suggesting a limited number of applications per year. Furthermore, the traditional control of postharvest infection in cold-stored table grapes can be achieved by repeated fumigation with sulfur dioxide or by the use of sulfur dioxide generating pads closed in polyethylene-lined grape containers. In the present study, the percentage of gray mold incidence was evaluated under natural and artificial conditions, after one month of cold storage and after one week of shelf life during regular and out of season crops. After a month in cold storage, it was observed that when grapes were subjected to $\mathrm{SO}_{2}$, the incidence of gray mold was reduced by $79.4 \%$ and $85.5 \%$ as compared to its control during out of season and regular crops, respectively. Under artificial conditions, sulfur dioxide reduced the incidence of Botrytis mold by $54.8 \%$ and $60 \%$ as compared to the control during out of season and regular crops, respectively. The results showed that, after seven days of shelf-life, under natural conditions, when grapes from out of season crop were subjected to $\mathrm{SO}_{2}$, the incidence of gray mold was reduced by $76.3 \%$ as compared to its control. In regular crop, the incidence of gray mold was reduced by $73.3 \%$ as compared to its control.

Under artificial conditions, sulfur dioxide reduced the incidence of Botrytis mold by $61.5 \%$ and $53 \%$ for out of season crop and regular crop, respectively, as compared to the controls. For the length of storage, it is important to find the best method of packaging that will minimize water loss and prevent both decay which would occur if $\mathrm{SO}_{2}$ is too low, and $\mathrm{SO}_{2}$ damage which would occur if $\mathrm{SO}_{2}$ is too high. Many countries have banned the use of sulfites on fresh fruit and vegetables, except on grapes, which are the only exception in most countries (Anonymous, 1986; Tongdee et al., 1991). An efficient procedure using a Sms pad in grapes, with acceptable residue levels has recently been suggested (Zutahy et al., 2008).

Usually, in the traditional grape areas in the world, there is just one crop per year (regular crop), which starts at the end of grapevine dormancy in late winter, and the harvest occurs during summer. However, in some subtropical areas, it is possible to obtain two crops of table grapes per year (regular and out of season crops). The regular crop starts from the end of grapevine dormancy in late winter and the harvest occurs during summer. Right after that, the grapevines are forced to sprout again by using budburst stimulators, a new bloom occurs and a new harvest (out of season crop) is obtained during autumn. The main difference between these two crops is that in the first one, the incidence of some fungal disease, such as downy mildew is low, whereas during the out of season crop, the incidence is higher due the most favorability for fungal infection (Ricce et al., 2013).

Gray mold can develop in the vineyard and spread rapidly among berries after harvest, during long distant transport, cold storage and shelf-life (Romanazzi et al., 2012). Grapes intended for storage of a few weeks or longer are stored at $0{ }^{\circ} \mathrm{C}$ in boxes with a dual release $\mathrm{SO}_{2}$ generating pad (quick release plus a slow release phase). This method can prevent decay caused by $B$. cinerea for a number of weeks. Few reports are related to the optimization of chemical control, such as the use of sulfur dioxide pads that release the appropriate dose of sulfur dioxide (Zoffoli et al., 2008 Zutahy et al., 2008).

A small segment of the population may experience severe allergic reactions to sulfites, and because of it, the Environmental Protection Agency (EPA) has proposed a $10 \mathrm{ppm}$ tolerance for sulfite residues in table grapes. Fruits with residues exceeding the tolerance are not allowed to be marketed. Vinifera grapes tolerate sulfur dioxide gas in concentrations that would damage other fruits, vegetables, eggs, meat, or poultry. Recently, it has been demonstrated that the amount of $\mathrm{SO}_{2}$ gas needed to kill Botrytis spores, or to inactivate exposed mycelium, is dependent on the concentration and the length of time the fungus is exposed to the fumigant (WFLO Commodity Storage Manual, 2008). During ocean shipment for periods longer than 10 days or long retail handling in which $\mathrm{SO}_{2}$, fumigation is not allowed, and the use of $\mathrm{SO}_{2}$-generating pads in combination with a box liner is advised for table grapes (Crisosto et al., 1994), what it is in accordance to the results here observed for 'BRS Vitoria' grape. These $\mathrm{SO}_{2}$-generating pads have sodium metabisulfite incorporated into them to allow a constant and slow release of $\mathrm{SO}_{2}$ during shipment and marketing. Also, because of increased interest in the export market, there is a need to use $\mathrm{SO}_{2}$ generating pads, especially for long-distance export marketing where grapes are in ocean transport for extended periods.

Our results proved that $\mathrm{SO}_{2}$ had no impact of its application on quality profile on 'BRS Vitoria' table grapes. It should be noted that the influence of treatments on flavor is often ignored because laboratory scale experiments tend to focus on the effectiveness of a treatment to control decay and do not sufficiently take into consideration the final quality of the product, which is essential for a potential commercial application (Romanazzi et al., 2012). The results of this study showed that bunch mass, berry firmness, mass loss, color, SS, TA and SS/TA of 'BRS Vitoria' was not consistently affected by $\mathrm{SO}_{2}$ treatment.

Palou et al. (2002) reported that individual berries were inoculated with $B$. cinerea and then exposed to a flow through fumigation system to simulate $\mathrm{SO}_{2}$ release from the slow release part of a dioxide-releasing pad. In this case, grapes are exposed continuously to the $\mathrm{SO}_{2}$, increasing the possibility of cumulative damage to the appearance and the taste of the berries. $\mathrm{No} \mathrm{SO}_{2}$ damage was found with a concentration of $3 \mu L^{-1}$ for $42 \mathrm{~d}$, but since $\mathrm{SO}_{2}$ absorption by berry is cumulative, a longer exposure time to the same $\mathrm{SO}_{2}$ concentration might cause damage. The release of the $\mathrm{SO}_{2}$ from the pads is a function of the humidity in boxes generated by grape respiration. The sodium metabisulfite in the pads is enclosed in a layer of plastic and paper, designed so that the paper gradually absorbs the water vapor and transmits it to the granules of sodium metabisulfite, which decomposes to $\mathrm{SO}_{2}$ and $\mathrm{H}_{2} \mathrm{O}$. In South Africa, it has been shown that a $\mathrm{SO}_{2}$ concentration around the grapes of 10 to $20 \mathrm{ppm}$ is safe and effective (Laszlo et al., 1981). It was found that concentrations of less than $7 \mathrm{ppm}$ in the fruit did not control decay if the storage temperature fluctuated above $0^{\circ} \mathrm{C}$, and that concentrations higher than $20 \mathrm{ppm}$ could injure the grapes by bleaching. Therefore, $\mathrm{a} \mathrm{SO}_{2}$ concentration of 7-10 ppm was recommended for long-term storage of grapes (Laszlo et al., 1981). To summarize, an efficient control of gray mold can be achieved on 'BRS Vitoria' seedless table grapes by sulfur dioxide during cold storage without affecting fruit quality.

\section{References}

Anonymous, 1986. GRAS status of outfitting agents for use on fresh and frozen foods revoked. Fed. Regist. 51, 25021. 
Borges, R.S., Roberto, S.R., Yamashita, F., Bonametti, J.B.O., Assis, A.M., 2012. Sensibilidade ao rachamento de bagas das videiras 'Concord', 'Isabel' e 'BRS Rúbea'. Rev. Bras. Fruticultura 34, 814-822.

Buffara, C.R.S., Angelotti, F., Vieira, F.A., Bogo, A., Tessmann, D.J., Bem, B.P., 2014 Elaboration and validation of a diagrammatic scale to assess downy mildew severity in grapevine. Ciên. Rural 44, 1384-1391.

Cappellini, R.A., Ceponis, M.J., Lightner, G.W., 1986. Disorders in table grape shipments to the New York market, 1972-1984. Plant Dis. 70, 1075-1079.

Crisosto, C.H., Smilanick, J.L., Dokoozlian, N.K., Luvisi, D.A., 1994. Maintaining table grape post-harvest quality for long distant markets. In: International Symposium on Table Grape Production, American Society for Enology and Viticulture, June 28 \& 29, p. 195-199.

Droby, S., Lichter, A., 2004. Post-harvest Botrytis infection: etiology, development and management. In: Elad, Y., Williamson, B., Tudzynski, P., Delen, N. (Eds.) Botrytis: Biology, Pathology and Control. Kluwer Academic Publishers, Dordrecht, The Netherlands, pp. 349-367.

Genta, W., Tessmann, D.J., Roberto, S.R., Vida, J.B., Colombo, L.A., Scapin, C.R., Ricce, W.S., Clovis, L.R., 2010. Manejo de míldio no cultivo protegido de videira de mesa ‘BRS Clara'. Pesqui. Agropecuária Bras. 45, 1388-1395.

Gubler, W.D., Marois, J.J., Bledsoe, A.M., Bettiga, L.J., 1987. Control of Botrytis bunch rot of grape with canopy management. Plant Dis. 71, 599-601.

Koyama, R., Assis, A.M., Yamamoto, L.Y., Borges, W.S., Prudencio, S.H., Roberto, S.R., 2014. Exogenous abscisic acid increases the anthocyanin concentration of berry and juice from 'Isabel' grapes (Vitis labrusca L.). HortScience 49, 460-464.

Lancaster, J.E., Lister, C., Reay, P.F., Triggs, C.M., 1997. Influence of pigment composition on skin color in a wide range of fruits and vegetables. J. Am. Soc. Hortic. Sci. 122, 594-598.

Laszlo, J., Combrink, J.C., Eksteen, G.J., Truter, A.B., 1981. Effect of temperature on the emission of sulphur dioxide from gas generators for grapes. Deciduous Fruit Grower 31, 112-119.

Luvisi, D., Shorey, H., Smilanick, J.L., Thompson, J., Gump, B.H., Knutson, J., 1992. Sulfur Dioxide Fumigation of Table Grapes. Bulletin 1932. University of California, Division of Agriculture and Natural Resources, Oakland, CA, USA, 21 pp.

Maia, J.D.G., Ritschel, P., Camargo, U.A., Souza, R.T., Fajardo, V.T., Naves, R.L. Girardi, C., 2014. 'BRS Vitoria'-a novel seedless table grape cultivar exhibiting special flavor and tolerance to downy mildew (Plamopara viticola). Crop Breed. Appl. Biotechnol. 14, 204-206.

Mattiuz, B., Miguel, A.C.A., Galati, V.C., Nachtigal, J.C., 2009. Efeito da temperatura no armazenamento de uvas apirênicas minimamente processadas. Rev. Bras.Fruticultura 31, 44-52.
McGuire, R.G., 1992. Reporting of objective color measurements. HortScience 27, 1254-1255.

Orak, H.H., 2007. Total antioxidant activities, phenolics, anthocyanins, polyphenoloxidase activities of selected red grape cultivars and their correlations. Sci. Hortic. 111, 235-241.

Palou, L., Crisosto, C.H., Garner, D., Basinal, L.M., Smilanick, J.L., Zoffoli, J.P., 2002. Minimum constant sulfur dioxide emission rates to control gray mold of cold stored table grapes. Am. J. Enol. Vitic. 52, 110-115.

Pearson, R.C., Goheen, A.C., 1988. Compendium of Grape Diseases. APS Press, MN USA, 96 pp.

Peppi, M.C., Fidelibus, M.W., Dokoozlian, N., 2006. Abscisic acid application timing and concentration affect firmness, pigmentation and color of 'Flame Seedless' grapes. HortScience 41, 1440-1445.

Rastija, V., Srecnik, G., Saric, M., 2009. Polyphenolic composition of Croatian wines with different geographical origins. Food Chem. 115, 54-60.

Ricce, W.S., Caramori, P.H., Roberto, S.R., 2013. Potencial climático para a produção de uvas em sistema de dupla poda anual no estado do Paraná. Bragantia 72 408-415.

Romanazzi, G., Lichter, A., Mlikota Gabler, F., Smilanick, J.L., 2012. Recent advances on the use of natural and safe alternatives to conventional methods to control postharvest gray mold of table grapes. Postharvest Biol. Technol. 63, 141-147.

Smilanick, J.L., Mansour, M.F., Mlikota Gabler, F., Margosan, D.A., Hashim-Buckey, J., 2010. Control of postharvest gray mold of table grapes in the San Joaquin Valley of California by fungicides applied during the growing season. Plant Dis. 94, 250-257.

Tongdee, S.C., Suwannagul, A., Neamprem, S., 1991. Postharvest handling of tender coconut. ASEAN Food J. 6, 74-75

Uquillas, C., Torres, E., Ibacache, A., Defillipi, B., 2013. 'Iniagrape-one', a new chilean table grape cultivar. HortScience 48, 501-503.

WFLO Commodity Storage Manual, 2008. Grapes, Fumigation with Sulfur Dioxide $\left(\mathrm{SO}_{2}\right), \mathrm{pp} 1-3$.

Youssef, K., Roberto, S.R., 2014a. Applications of salt solutions before and after harvest affect the quality and incidence of postharvest gray mold of 'Italia' table grapes. Postharvest Biol. Technol. 87, 95-102.

Youssef, K., Roberto, S.R., 2014b. Salt strategies to control Botrytis mold of 'Benitaka' table grapes and to maintain fruit quality during storage. Postharvest Biol. Technol. 95, 95-102.

Zoffoli, J.P., Latorre, B.A., Naranjo, P., 2008. Hairline, a postharvest cracking disorder in table grapes induced by sulfur dioxide. Postharvest Biol. Technol. 47,90-97.

Zutahy, Y., Lichter, A., Kaplunov, T., Lurie, S., 2008. Extended storage of 'Red Globe' grapes in modified $\mathrm{SO}_{2}$ generating pads. Postharvest Biol. Technol. 50, 12-17. 